\title{
Exploring The Relationship Between Gratitude And Economic Perceptions
}

Dora E. Bock, Georgia Southern University, USA

Jacqueline K. Eastman, Georgia Southern University, USA

Benjamin P. McKay, Georgia Southern University, USA

\begin{abstract}
This study explores the associations between consumer gratitude and perceptions of consumer confidence and economic welfare. From a random stratified sample of adults living in the southeastern U.S., the findings reveal that a grateful outlook is positively associated with favorable perceptions of the U.S. economy, state economy, future job growth, and future income earned. Additionally, the results indicate significant differences between grateful and ungrateful individuals in terms of their perceptions of the U.S. economy, job growth, and anticipated income for the upcoming year. The results suggest that managers may want to focus on developing strong relationships with grateful customers, given that grateful customers may help firms survive tough economic times.
\end{abstract}

Keywords: Gratitude; Economic Perceptions; Consumer Confidence; Broaden-and-Build Theory

\section{INTRODUCTION}

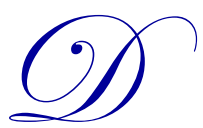

uring the Great Recession, spanning from December 2007 until summer 2009, the United States alone experienced a loss of over 10 million jobs, an unemployment rate well above 9 percent, and over a 5 percent decline in gross domestic product (Goldsmith and Diette, 2012). Not surprisingly, the economic devastation has resulted in decreased consumer confidence and heightened economic pessimism. While research has investigated effects of the Great Recession, and particularly job loss on mental and physical health (Bassett, 2010; Goldsmith and Diette, 2012; Rabin, 2009), limited research has been conducted on understanding what causes individuals to have more favorable perceptions of economic, employment and family welfare and consumer confidence. This sense of positivity is critical given the decline in mental health and increased depression rates of U.S. citizens that have been associated with the Great Recession (Sentementes, 2010).

We believe that gratitude is one mechanism which can buffer individuals in tough economic times. Research has indicated that having a sense of gratitude can alter one's attention towards the positive in life (Wood et al., 2010), and therefore lead to positive outcomes such as improved life satisfaction and subjective well-being (Fagley, 2012; Lambert et al., 2009a; Watkins et al., 2003). While gratitude research has investigated the importance of gratitude in relationships (Algoe et al., 2008; Algoe and Haidt, 2009; Bartlett and Desteno, 2006; Tsang, 2006; Watkins et al., 2006), exchanges (Morales, 2005; Palmatier et al., 2009; Soscia, 2007), and well-being (Fagley, 2012; Fredrickson et al., 2003; Watkins et al., 2003), no research has studied the potential relationships among gratitude, consumer welfare and consumer confidence. As the marketing literature suggests that gratitude has positive implications for businesses in terms of favorable word-of-mouth (Soscia, 2007), purchase intention, trust (Palmatier et al., 2009), affective commitment (Raggio and Folse, 2009) and satisfaction (Morales, 2005), it is vital for businesses consider the role of gratitude during tough economic times.

In this article, we address this gap in the literature and offer further evidence supporting the positive effects of gratitude. The remainder of this article is composed of four parts. First, we review the extant literature regarding the conceptualization, measurement, and importance of gratitude. Next, we discuss the method utilized, which is followed by a summarization of the findings. The article concludes by offering theoretical implications and suggestions for future research. 


\section{LITERATURE REVIEW}

Gratitude research dates back to the late 1700s in the works by Adam Smith, although it has not been until recently that research has more fully investigated the importance of gratitude in well-being (Fagley, 2012; Fredrickson et al., 2003; Watkins et al., 2003) and social (Algoe et al., 2010; Tsang, 2006; Wood et al., 2008b) and buyer-seller relationships (Morales, 2005; Palmatier et al., 2009; Raggio et al., 2013; Soscia, 2007). The concept of gratitude lacks a simple conceptualization as a result of being defined as an emotion (Fredrickson et al., 2003), a moral affect (McCullough et al., 2001), a disposition or personality trait (McCullough et al., 2002; Watkins et al., 2003; Wood et al., 2008b), an attitude and a life orientation (Wood et al., 2010).

When conceptualized as an emotion, gratitude results from receiving a benefit from another (Emmons and McCullough, 2003; Weiner, 1985; Fredrickson, 2003). McCullough, et al. (2008, p. 281) define gratitude as "a positive emotion that typically flows from the perception that one has benefited from the costly, intentional, voluntary action of another person." The research investigating gratitude, as an emotion, often examines the causes and consequences of gratitude (Morales, 2005; Palmatier et al., 2009; Soscia, 2007; Tsang, 2006).

Concurring with emotion conceptualizations, trait research tends to conceptualize grateful individuals as those being prone to experiencing gratitude as an emotion (McCullough et al., 2002; Watkins et al., 2003). Specifically, McCullough et al. (2002, p. 112) define the grateful disposition "as a generalized tendency to recognize and respond with grateful emotion to the roles of other people's benevolence in the positive experiences and outcomes that one obtains." This definition articulates the tendency to respond with gratitude. McCullough et al. (2002) further operationalize the grateful disposition as possessing four components: intensity, grateful individuals may have more intense feelings of gratitude; frequency, grateful individuals may report more daily feelings of gratitude and feel grateful for even small acts of kindness; span, grateful individuals may feel gratitude for many aspects of life; and density, after receipt of a positive outcome, grateful individuals may feel gratitude towards many people. Similar to McCullough et al.'s (2002) use of the word "tendency," Watkins et al. (2003, p. 432) define the grateful disposition as "the predisposition to experience the state of gratitude." Watkins et al. (2003) argue that people who possess a grateful disposition have three characteristics. First, they have a sense of abundance and do not feel deprived in life; second, they have an appreciation of the simple pleasures that are typical in everyday life; and third, they appreciate the contribution of others to their well-being and quickly recognize this contribution (Watkins et al., 2003). While these conceptualizations of trait gratitude incorporate the proneness to feel the grateful emotion, trait researchers have articulated that gratitude does not only result from receiving a benefit, instead individuals can feel grateful for their families, health, employment and life itself. This notion of feeling widespread gratitude is recognized in McCullough et al.'s (2002) characterization of span and Watkins et al. (2003) characterization of appreciating the simple pleasures of life.

Recent work has acknowledged the divergence in gratitude conceptualizations (Lambert et al., 2009b) and suggests that gratitude is more than simply appreciating benefits received from another (Wood et al., 2010). Adler and Fagley (2005) take a broader approach in which they view gratitude as only one of eight components of a more holistic appreciation construct. In their work, appreciation is defined as "acknowledging the value and meaning of something — an event, a person, a behavior, an object — and feeling a positive emotional connection to it" (p. 81); whereas they conceptualize gratitude as "noticing and acknowledging a benefit that has been received, whether from another person or a deity, and feeling thankful for the efforts, sacrifices, and actions of an other" (p. 83). Thus, appreciation is viewed much more holistically, while the gratitude component reflects prior work conceptualizing the concept as an emotion. Further encouraging a broader approach to gratitude and arguing that prior conceptualizations fail to take into consideration reported sources of gratitude (e.g. waking up in the morning, one's abilities, etc.), Wood et al. (2010) suggest a life orientation conceptualization of gratitude. This generalized approach conceptualizes gratitude as "part of a wider life orientation towards noticing and appreciating the positive in the world," (Wood et al., 2010, p. 891). This recent conceptualization articulates that individuals can feel grateful towards anything in the world, and this fosters personally and socially productive behaviors.

\section{Measuring Gratitude}

Resulting from the various conceptualizations of gratitude, different measurement approaches have been taken. When considering gratitude as an emotion, most researchers tend to incorporate a three-item scale, containing 
the items "grateful," "thankful," and "appreciative." Three scales have been developed to measure trait gratitude and appreciation, including the GQ-6, GRAT Scale, and Appreciation Scale. The six-item GQ-6, developed by McCullough et al. (2002), views trait gratitude as a unidimensional construct, and measures the frequency, intensity, span and density of one's gratitude. A representative item includes "I have so much in life to be thankful for." The forty-four item GRAT Scale, developed by Watkins et al. (2003), considers gratitude a multidimensional construct, comprising of the following three dimensions: (1) A sense of abundance, (2) Simple appreciation, and (3), appreciation of others. Lastly, the fifty-seven item Appreciation Scale developed by Adler and Fagley (2005) is another potential measure of gratitude; however, Adler and Fagley (2005) consider gratitude as a single component of a more holistic appreciation construct. The multidimensional Appreciation Scale consists of the following dimensions: (1) have focus, (2) awe, (3) ritual, (4) present moment, (5) self/social comparison, (6) gratitude, (7) loss/adversity, and (8) interpersonal.

Recent work analyzing the relationships shared among the twelve dimensions that result from summing the GQ6, GRAT and Appreciation Scales reveals that these scales are highly intercorrelated (Wood et al., 2008b). Furthermore, a series of exploratory and confirmatory factor analyses lend support for a one-factor solution of gratitude; therefore, suggesting the combination of appreciation and gratitude literatures and further encouraging the life orientation conceptualization of gratitude (Wood et al., 2010).

\section{The Importance of Gratitude}

Gratitude is a prevalent and constructive emotion. In fact, gratitude has been noted as the second most common emotion, only followed by joy (Fredrickson, 2009). Likewise, in a survey by Sommers and Kosmitzki (1988), $10 \%-30 \%$ of the participants indicated that they experience gratitude "regularly and often," and participants also indicated that gratitude is considered a useful and constructive emotion.

Gratitude has been argued to function as a moral motivator, promoting individuals to behavior pro-socially (McCullough et al., 2001); and this notion has been confirmed through several studies demonstrating the ability of gratitude to foster positive social relationships and promote prosocial behavior (Algoe et al., 2008; Algoe and Haidt, 2009; Bartlett and Desteno, 2006; Tsang, 2006; Watkins et al., 2006). While gratitude has been predominantly studied in the psychology domain, marketing research has begun to investigate the importance of gratitude in buyerseller relationships. Through studying gratitude as an emotion experienced by customers, as noted earlier, findings in marketing reveal that customer felt gratitude is positively correlated with favorable word-of-mouth (Soscia, 2007), purchase intentions, trust (Palmatier et al., 2009), affective commitment (Raggio and Folse, 2009) and satisfaction (Morales, 2005). Consistent with reciprocity theory, these works converge on the notion that when customers feel gratitude, they want to reciprocate to their benefactor (seller, agent, sales representative, etc.), which can help these buyer-seller relationships flourish (Palmatier, 2008; Raggio et al., 2013).

Findings also demonstrate trait gratitude has a pronounced effect on individual well-being. McCullough et al. (2002) find that trait gratitude is positively correlated with positive affect, well-being, and pro-social behaviors, and negatively correlated with envy and materialistic attitudes. Gratitude can also help reduce worry (Geraghty et al., 2010), decrease stress (Wood et al., 2008a), enhance sleep quality (Wood et al., 2009), increase one's concern for corporate social responsibility (Anderson et al., 2006), combat depression (Fredrickson et al., 2003; Watkins et al., 2003) and lead to higher levels of life satisfaction (Fagley, 2012; Lambert et al., 2009a; Watkins et al., 2003). More recent work has further investigated gratitude's negative relationship with materialism (Lambert et al., 2009a; Polak and McCullough, 2006), and has demonstrated that it is gratitude's positive effect on life satisfaction that explains the reduced materialism of grateful individuals (Lambert et al., 2009a). Together, these findings support the importance of gratitude in everyday life.

Favorable effects from gratitude are often explained by Fredrickson's $(1998,2001)$ broaden-and-build theory of positive emotions. This theory articulates that positive emotions, including gratitude, possess the capability to put an individual's mind and body at ease and broaden one's cognitive and social resources. While negative emotions tend to narrow one's thinking, positive emotions can expand one's attention, thought-action repertoires, and improve coping processes (See Fredrickson et al., 2003 for a review). Fredrickson et al. (2003, p. 367) state, "Over time, the broadening triggered by positive emotions builds a range of personal resources, including physical 
resources (e.g., physical skills, health, longevity), social resources (e.g., friendships, social support networks), intellectual resources (e.g., expert knowledge, intellectual complexity), and psychological resources (e.g., resilience, optimism, creativity)."

\section{Research Questions}

Given recent economic conditions, it appears relevant and important to understand characteristics that may lead individuals to have optimistic views on economic, employment, and family welfare (i.e. consumer welfare) as well as consumer confidence. We operationalize consumer welfare as consumers' perceptions of their current financial standing as well as current country and state conditions, and we operationalize consumer confidence as consumers' perceptions of future business conditions, job availability, and income (Bechtel, 2008). While research has demonstrated favorable effects of gratitude, limited research has investigated gratitude's effect on these important perceptions. In agreement with broaden-and-build theory, it seems reasonable that gratitude may serve a vital function in such times. Given that positive emotions broaden and build physical, intellectual psychological, and social resources, as well as the notion that grateful individuals notice and appreciate the positive in the world, we believe that gratitude should be positively associated with perceptions of consumer welfare and confidence. Thus, two fundamental research questions emerge:

RQ1: Does a positive relationship exist among gratitude and perceptions of (a) consumer welfare and (b) consumer confidence?

RQ2: Do grateful consumers, rather than ungrateful consumers, score higher on perceptions of (a) consumer welfare and (b) consumer confidence?

\section{METHODOLOGY}

To examine the research questions the authors chose to conduct a telephone survey that focused on households in the state of Georgia. The phone list used to collect the data was purchased from InfoUSA. This survey was conducted in late October of 2012 over a five night time frame. To assist in data collection, trained undergraduates enrolled in a marketing research course administered the interviews. In total, 295 responses were gathered which equated to an approximate 9 percent response rate.

\section{Sample}

Compared to the Census Bureau's (2011) demographics of the state of Georgia, the sample was skewed toward female, white, older, married and college educated consumers. Specifically, the sample was 59\% female compared to the $51 \%$ female reported by the Census Bureau for the state of Georgia. The median age of the sample also skewed older (median age category of 46 to 55) compared to the 35.5 years reported by the Census Bureau. The sample included more educated consumers, such that $28.3 \%$ held a college degree compared to the $17.7 \%$ noted by the Census Bureau. Finally, 79.5\% and $13.8 \%$ of the sample was Caucasian and African American, respectively, compared to the $62.3 \%$ and $31.9 \%$ reported by the Census Bureau. Table 1 presents the demographic information of the sample. 
Table 1: Sample Demographics

\begin{tabular}{|c|c|c|}
\hline Gender & $\begin{array}{c}\text { Male } \\
\text { Female }\end{array}$ & $\begin{array}{l}41 \% \\
59 \%\end{array}$ \\
\hline Ethnicity & $\begin{array}{c}\text { White } \\
\text { African American } \\
\text { Some Other Race } \\
\text { Other }\end{array}$ & $\begin{array}{l}79.5 \% \\
13.8 \% \\
2.1 \% \\
4.6 \%\end{array}$ \\
\hline Marital Status & $\begin{array}{c}\text { Married } \\
\text { Single (Never Married) } \\
\text { Widowed } \\
\text { Divorced } \\
\text { Separated } \\
\text { Unmarried } \\
\text { Not Specified }\end{array}$ & $\begin{array}{l}61.1 \% \\
15.2 \% \\
10.2 \% \\
9.2 \% \\
1.8 \% \\
1.8 \% \\
0.7 \%\end{array}$ \\
\hline Age & $\begin{array}{c}18-25 \\
26-35 \\
36-45 \\
46-55 \\
56-65 \\
\text { Over } 65 \\
\text { Not Specified }\end{array}$ & $\begin{array}{r}7.8 \% \\
5.3 \% \\
11.0 \% \\
26.9 \% \\
20.8 \% \\
27.9 \% \\
0.3 \%\end{array}$ \\
\hline Education & $\begin{array}{c}\text { High School or Less } \\
\text { High School Graduate } \\
\text { Some College } \\
\text { 2-year Associate Degree } \\
\text { 4-year College Degree } \\
\text { Some Graduate School } \\
\text { Graduate Degree } \\
\text { Not Specified }\end{array}$ & $\begin{array}{c}4.6 \% \\
16.6 \% \\
17.7 \% \\
9.9 \% \\
28.3 \% \\
3.9 \% \\
18.7 \% \\
0.3 \%\end{array}$ \\
\hline
\end{tabular}

\section{Measures}

Since the GQ-6 is frequently used to measure gratitude (Anderson et al., 2006; Fagley, 2012; Lambert et al., 2009a; McCullough et al., 2002) and prior research supports high correlations among the GQ-6 and the eleven existing gratitude subscales (Wood et al., 2008b), we opted to use the measure in our study. The six items utilized a seven point scale and included "I have so much in life to be thankful for," "If I had to list everything that I felt grateful for, it would be a very long list," "When I look at the world, I don't see much to be grateful for," "I am grateful to a wide variety of people," "As I get older I find myself more able to appreciate the people, events, and situations that have been a part of my life history," and "Long amounts of time can go by before I feel grateful to something or someone."

Four items utilizing a three point scale were used to measure consumer welfare, including "Do you think the United States economy today is worse, about the same, or better than it was at this time last year" (Gallup, 2012), "Compared to last year are you and your family living with you worse, about the same, or better off financially" (Ludvigson, 2004); "During the past year, has your family's salary not kept up, has somewhat kept up, or has kept up with the cost of living," (Survey Research Center Institute for Social Research, The University of Michigan (2009, A15 \& A14); and "Do you think the Georgia economy today is worse, about the same, or better than it was at this time last year" (Gallup, 2012).

Three items adapted from Ludvigson (2004) and Bechtel (2008), measured on a three item scale, were used to measure consumer confidence: "Looking ahead one year from now, do you think general business conditions in Georgia will be worse, about the same, or better"; "Looking ahead on year from now, do you think there will be fewer, about the same, or more jobs available in Georgia"; and "Looking ahead one year, do you think your total 
family income (all wage earners living with you) will be lower than it is now, about the same as it is now, or higher than it is now."

\section{RESULTS}

Exploratory factor analysis was used to assess the psychometric properties of the consumer welfare, consumer confidence, and gratitude scales. One factor solutions, explaining more than $50 \%$ of the variance as well as maintaining adequate loadings were found for each the consumer welfare and consumer confidence scales, thus adhering to recommended guidelines (Hair et al., 2009). The reliability of the consumer welfare scale was .76, while the reliability of the consumer confidence scale was .75 . When evaluating the gratitude items, a two factor solution emerged, such that the reverse coded items "When I look at the world, I don't see much to be grateful for" and "Long amounts of time can go by before I feel grateful to something or someone" loaded to a separate factor. Nonetheless, the solution satisfied recommendations, such that items loaded greater than .7 and explained more than $50 \%$ of the variance. Given that research indicates that reverse coded items can possess less than ideal psychometric properties and distort the factor structure (Weijters and Baumgartner, 2012), and given the prevalent use and support of a unidimensional G6 gratitude scale (Anderson et al., 2006; Fagley 2012; Lambert et al., 2009; McCullough et al., 2002), all six items were retained for future analyses. The reliability of the G6 was .68.

To examine RQ1, a summated gratitude scale was first created by summing and averaging the G6 items. While exploratory factor analysis yielded support for consumer welfare and confidence items to be summated to create two constructs, the authors decided not to summate these scales given the diversity within each measure (perceptions of the economy, financial well-being, general business conditions, employment, etc.). Then, a correlational analysis was conducted (See Table 2). The correlations indicated that gratitude was positively related to individuals perceiving the State and Country economic conditions as being better than last year, and that gratitude was positively related to favorable outlooks regarding future job growth and total family income; however gratitude failed to relate to current perceptions of family financial status and future expectations regarding general business conditions. These results indicate that a grateful outlook does impact certain perceptions of consumer welfare and consumer confidence.

Table 2: Correlations

\begin{tabular}{|c|c|c|c|c|c|c|c|c|c|c|}
\hline Variable & $\mathbf{M}$ & SD & Range & Gratitude & SE & CFS & CSC & FBC & FJG & FFI \\
\hline Gratitude & 6.33 & .63 & $1-7$ & 1 & & & & & & \\
\hline USE & 1.77 & .78 & $1-3$ & $.17 * *$ & 1 & & & & & \\
\hline CFS & 1.88 & .65 & $1-3$ & .08 & $.47 * *$ & 1 & & & & \\
\hline CSC & 1.83 & .84 & $1-3$ & .05 & $.33 * *$ & $.48^{* *}$ & 1 & & & \\
\hline FBC & 2.4 & .76 & $1-3$ & -.03 & $.30 * *$ & $.17 * *$ & $.18 * *$ & 1 & & \\
\hline FJG & 2.36 & .73 & $1-3$ & $.13^{*}$ & $.41 * *$ & $.27 * *$ & $.25 * *$ & $.63 * *$ & 1 & \\
\hline FFI & 2.21 & .62 & $1-3$ & $.11^{*}$ & $.32 * *$ & $.36^{* *}$ & $.33 * *$ & $.40 * *$ & $.42 * *$ & 1 \\
\hline SE & 1.82 & .73 & $1-3$ & $.11 *$ & $.66 * *$ & $.43 * *$ & $.27 * *$ & $.40 * *$ & $.39 * *$ & $.32 * *$ \\
\hline
\end{tabular}

** Correlation is significant at the 0.01 level (1-tailed). * Correlation is significant at the 0.05 level (1-tailed). USE $=$ current perceptions of the country economic conditions, CFS = perceptions of current financial standing compared to last year, $\mathrm{CSC}=$ perceptions that one's current salary has kept up with the cost of living, $\mathrm{FBC}=$ perceptions of future business conditions, FJG = perceptions of future job growth, FFI = perceptions of future total family income, $\mathrm{SE}=$ current perceptions of the state economic conditions.

To assess RQ2, a tertiary split was first performed to separate grateful and ungrateful individuals. Those falling within the bottom and top tiers were included in the subsequent analyses (participants scoring less than 6.0 were classified as ungrateful individuals, while those scoring higher than 6.67 were classified as grateful). The results indicated that grateful participants scored higher than ungrateful participants on certain perceptions of welfare and consumer confidence, but not on all perceptions, although mean scores were in the predicted direction. Grateful participants scored higher than ungrateful participants on perceptions of the country economy (1.86 vs 1.62), future job growth (2.47 vs 2.17), and future total family income (2.27 vs 2.05) (See Table 3). 
Table 3: T-Tests of Differences between Grateful and Ungrateful Individuals

\begin{tabular}{|c|c|c|c|c|}
\hline Variable & Range & Grateful & Ungrateful & T-test \\
\hline USE & $1-3$ & 1.86 & 1.62 & $-2.03 *$ \\
\hline CFS & $1-3$ & 1.89 & 1.76 & -1.35 \\
\hline $\mathrm{CSC}$ & $1-3$ & 1.88 & 1.68 & -1.61 \\
\hline FBC & $1-3$ & 2.35 & 2.33 & -.13 \\
\hline FJB & $1-3$ & 2.47 & 2.18 & $-2.41 *$ \\
\hline FFI & $1-3$ & 2.27 & 2.06 & $-2.28 *$ \\
\hline SE & $1-3$ & 1.90 & 1.72 & -1.54 \\
\hline
\end{tabular}

* Difference is significant at the 0.05 level (2-tailed). USE = current perceptions of the country economic conditions, CFS $=$ perceptions of current financial standing compared to last year, $\mathrm{CSC}=$ perceptions that one's current salary has kept up with the cost of living, FBC = perceptions of future business conditions, FJG = perceptions of future job growth, FFI = perceptions of future total family income, $\mathrm{SE}=$ current perceptions of the state economic conditions.

\section{CONCLUSION}

While recessionary periods can have pronounced effects on human health, our results suggest that gratitude is one mechanism that may lead consumers to have more optimism and favorable views of the economy. Particularly we found that individuals who scored highly on the GQ-6 also held more favorable views of the state and country economy, and were more confident in future job growth and future family income. Together these findings address RQ1, by demonstrating that gratitude does have a favorable relationship with some perceptions of consumer welfare and consumer confidence. Interestingly, we failed to find any relationship between gratitude and future expectations of general business conditions and also found no relationship between gratitude and perceptions of one's current financial standing. Given that salaries are objective, individuals can readily evaluate one's earnings compared to prior years. Therefore, perceptions of one's current financial standing, as well as perceptions of whether one's salary has kept up with the cost of living, may not be the types of perceptions influenced by gratitude.

Similar to the findings in regards to RQ1, in terms of RQ2, we also found that grateful individuals scored higher on some perceptions of consumer welfare and consumer confidence. Specifically, we find that grateful individuals felt that the current economy had improved compared to last year more so than ungrateful individuals. In addition, grateful individuals held significantly higher perceptions of future job growth and future total family income. Consumers with a higher sense of gratitude see the economy, future job growth, and future total family income more positively than ungrateful consumers. Together, these findings add to the literature supporting the positive effects of gratitude, and concur with broaden-and-build theory, such that gratitude can broaden one's mindset and function as a coping mechanism in tough economic times.

This research does present some compelling managerial implications. Given that consumer confidence is related to consumer spending, and the current research finds that gratitude is associated with certain aspects of consumer welfare and confidence, managers may want to target consumers high in gratitude since these consumers may be likely to spend more. To reach these high gratitude consumers, marketers may want to use the theme of being thankful to a wide variety of people who have helped them over time (such as to their customers and business partners) to spur feelings of gratitude. Thus, this group of consumers may help firms survive in tough economies.

Nonetheless, our research does have some shortcomings. To begin with, the response rate was relatively low, which was likely due to two factors. First, phone calls were made near the time of the 2012 presidential election campaign. Calls were made using Google voice, which was the same method used by the Republican Party to fundraise and verify voter turnout. Throughout the data collection, many of the telephone calls went unanswered, which is likely due to the high number of political calls being made at the same time (Hamby, 2012). Second, student volunteers under the supervision of the authors were used to help gather data. These volunteers were trained on proper data collection techniques and procedures, however, the majority of the students lacked telemarketing experience. Together, these two factors limited the ability to increase the response rate on this survey. Lastly, the phone list purchased did not include cell phones, which could have influenced the final makeup of our sample. Although the research does have limitations, the results found in this exploratory study are consistent with existing research demonstrating the beneficial effects of gratitude. Given these findings, we suggest future work further explore the association between gratitude and perceptions of consumer welfare and confidence. 


\section{AUTHOR INFORMATION}

Dora E. Bock is an Assistant Professor of Marketing at Georgia Southern University. She received her Ph.D. in marketing from Louisiana State University. E-mail: dbock@georgiasouthern.edu

Jacqueline K. Eastman is a Professor of Marketing at Georgia Southern University. She received her Ph.D. in marketing from Florida State University. E-mail: jeastman@ georgiasouthern.edu (Corresponding author)

Benjamin P. McKay is a research specialist at Georgia Southern University in the Department of Business Research and Economic Development. E-mail: bpmckay@georgiasouthern.edu

\section{REFERENCES}

1. Algoe, S., Gable, S.L. and Maisel, N.C. (2010). It's the little things: Everyday gratitude as a booster shot for romantic relationships. Personal Relationships, 17(2), 217-233.

2. Algoe, S.B., Haidt, J. and Gable, S.L. (2008). Beyond reciprocity: Gratitude and relationships in everyday life. Emotion, 8, 425-429.

3. Algoe, S.B. and Haidt, J. (2009). Witnessing excellence in action: The 'other-praising' emotions of elevation, gratitude, and admiration. Journal of Positive Psychology, 4, 105-127.

4. Adler, M.G. and Fagley, N.S. (2005). Appreciation: Individual differences in finding value and meaning as a unique predictor of subjective well-being. Journal of Personality, 73(1), 79-114.

5. Anderson, L.M., Giacalone, R.A. and Jurkiewicz, C.L. (2006). On the relationship of hope and gratitude to corporate responsibility. Journal of Business Ethics, 70, 401-409.

6. Bassett, L. (2010). Study: Long term unemployment has disastrous effects on health and longevity. Available at http://www.huffingtonpost.com/2010/11/05/study-longterm-unemployme_n_779743.html (accessed 21 January 2013).

7. Bartlett, M.Y. and DeSteno, D. (2006). Gratitude and prosocial behavior: helping when it costs you. Psychological Science. 17, 319-325.

8. Bechtel, G. (2008). A Dual Source Indicator of Consumer Confidence. Sociological Methodology, 26(1), 299-324.

9. Census Bureau of the United States (2010). Profile of general population and housing characteristics: 2010 demographic profile data. retrieved from http://factfinder2.census.gov/bkmk/table/1.0/en/DEC/10_DP/DPDP1/0400000US13

10. Emmons, R.A. and McCullough, M.E. (2003). Counting blessings versus burdens: An experimental investigation of gratitude and subjective well-being in daily life. Journal of Personality and Social Psychology, 84(2), 377-389.

11. Fagley, N.S. (2012). Appreciation uniquely predicts life satisfaction above demographics, the Big 5 personality factors and gratitude. Personality and Individual Differences, 53, 59-63.

12. Fredrickson, B.L. (1998). What are good positive emotions? Review of General Psychology, 2, 300-319.

13. Fredrickson, B.L. (2001). The role of positive emotions in positive psychology: The broaden-and-build theory of positive emotions. American Psychologist, 56, 218-226.

14. Fredrickson, B.L. (2009). What are the top 10 positive emotions? Available at: http://www.huffingtonpost.com/kari-henley/what-are-the-top-10-posit_b_203797.html (accessed 9 January 2013).

15. Fredrickson, B.L. and Levenson, R.W. (1998). Positive emotions speed recovery from the cardiovascular sequelae of negative emotions. Cognition and Emotion, 12, 191-220.

16. Fredrickson, B.L., Mancuso, R.A., Branigan, C. and Tugade, M. (2000). The undoing effect of positive emotions. Motivation and Emotion, 24, 237-258.

17. Fredrickson, B.L., Tugade, M.M., Waugh, C.E. and Larkin, G.R. (2003). What are good positive emotions in crises? A prospective study of resilience and emotions following the terrorist attacks on the United States on September 11 $1^{\text {th }}$, 2001. Journal of Personality and Social Psychology. 84(2), 365-376.

18. Gallup. (2012). U.S. economic outlook is retrieved from http://www.gallup.com/poll/110824/gallup-dailyus-economic-outlook.aspx 
19. Geraghty, A.W.A., Wood, A.M. and Hyland, M.E. (2010). Dissociating the facets of hope: Agency and pathways predict dropout from unguided self-help therapy in opposite directions. Journal of Research in Personality. 44, 155-158.

20. Goldsmith, A. and Diette, T. (2012). Exploring the link between unemployment and mental health outcomes. Available at: http://www.apa.org/pi/ses/resources/indicator/2012/04/unemployment.aspx (accessed 10 January 2013).

21. Hair, J.F., Black, W.C., Babin, B.J. and Anderson, R.E. (2009). Multivariate Data Analysis, $7^{\text {th }}$ edition, Prentice Hall, Englewood Cliffs, NJ.

22. Hamby, P. (2012). Analysis: Why Romney lost. Available at: http://www.cnn.com/2012/11/07/politics/why-romney-lost (accessed 24 June 2013).

23. Lambert, N.M., Fincham, F.D., Stillman, T.F. and Dean, L.R. (2009a). More gratitude, less materialism: The mediating role of life satisfaction. The Journal of Positive Psychology. 4(1), 32-42.

24. Lambert, N.M., Graham, S.M. and Fincham F.D. (2009b). A prototype analysis of gratitude: Varieties of gratitude experiences. Personality and Social Psychology Bulletin. 35(9), 1193-1207.

25. Ludvigson, S.C. (2004). Consumer Confidence and Consumer Spending. Journal of Economic Perspectives.18(2), 29-50.

26. McCullough, M.E., Emmons, R.A. and Tsang, J. (2002). The grateful disposition: A conceptual and empirical topography. Journal of Personality and Social Psychology. 82(1), 112-127.

27. McCullough, M.E., Kilpatrick, S.D., Emmons, R.A. and Larson, D.B. (2001). Is gratitude a moral affect? Psychological Bulletin. 127(2), 249-256.

28. McCullough, M.E., Kimeldorf, M.B., and Cohen, A.D. (2008). An adaptation for altruism? The social causes, social effects, and social evolution of gratitude. Current Directions in Psychological Science. 17(4), 281-85.

29. Morales, A.C. (2005). Giving firms an "E" for effort: Consumer responses to high-effort firms. Journal of Consumer Research. 31(4), 806-12.

30. Palmatier, R.W. (2008). Relationship Marketing. Marketing Science Institute, Cambridge, MA.

31. Palmatier, R.W., Jarvis, C.B., Bechkoff, J.R. and Kardes, F.R. (2009). The role of customer gratitude in relationship marketing. Journal of Marketing. 73(5), 1-18.

32. Polak, E.L. and McCullough, M.E. (2006). Is gratitude an alternative to materialism? Journal of Happiness Studies. 7, 343-360.

33. Rabbin, R.C. (2009). Unemployment may be hazardous to your health. Available at http://www.nytimes.com/2009/05/09/health/09sick.html? r=0 (accessed 21 January 2013).

34. Raggio, R.D. and Folse, J.A.G. (2009). Gratitude works: Its impact and the mediating role of affective commitment in driving positive outcomes. Journal of the Academy of Marketing Science. 37(4), 455-469.

35. Raggio, R.D., Walz, A., Bose, M. and Folse, J.A.G. (2013). Gratitude in relationship marketing: Theoretical development and directions for future research. European Journal of Marketing, forthcoming.

36. Sentementes, G.G. (2010). The recession's psychological toll: Layoffs, workplace uncertainty stress workers and companies. Available at http://articles.baltimoresun.com/2010-05-31/business/bs-bz-workermental-health-20100530_1 mental-illness-health-benefits-magellan-health-services (accessed 21 January 2013).

37. Smith, A. (1976). The Theory of Moral Sentiments (6th ed.). Clarendon Press, Oxford, England. (Original work published in 1790).

38. Sommers, S. and Kosmitzki C. (1988). Emotion and social context: An American-German comparison. British Journal of Social Psychology. 27, 35-49.

39. Soscia, I. (2007). Gratitude, delight, or guilt: The role of consumers' emotions in predicting postconsumption behaviors. Psychology \& Marketing. 24(10), 871-94.

40. The University of Michigan, Survey Research Center Institute for Social Research, Survey of Consumers Questionnaire, http://www.psc.isr.umich.edu/dis/data/kb/downloads/T1065_SCA questionnaire.pdf

41. Tsang, J. (2006). Brief report gratitude and prosocial behaviour: An experimental test of gratitude. Cognition \& Emotion. 20(1), 138-148.

42. Watkins, P.C., Sheer, J., Ovnicek, M. and Kolts, R. (2006). The debt of gratitude: Dissociating gratitude and indebtedness. Cognition and Emotion. 20, 217-241. 
43. Watkins, P.C., Woodward, K., Stone, T. and Kolts, R.L. (2003). Gratitude and happiness: Development of a measure of gratitude, and relationships with subjective well-being. Social Behavior and Personality. $31(5), 431-452$.

44. Weijters, B. and Baumgartner H. (2012). Misresponse to reverse and negative items in surveys: A review. Journal of Marketing Research. 49(5), 737-747.

45. Weiner, B. (1985). An attributional theory of achievement motivation and emotion. Psychological Review. 92, 548-573.

46. Wood, A.M., Froh, J.J. and Geraghty, A.W.A. (2010). Gratitude and well-being: A review and theoretical integration. Clinical Psychology Review. 30, 890-905.

47. Wood, A.M., Joseph, L., Lloyd, J. and Atkins, S. (2009). Gratitude influences sleep through the mechanism of pre-sleep cognitions. Journal of Psychosomatic Research. 66, 43-48.

48. Wood, A.M., Maltby, J., Gillett, R., Linley, P.A. and Joseph, S. (2008a). The role of gratitude in the development of social support, stress, and depression: Two longitudinal studies. Journal of Research in Personality. 42, 854-871.

49. Wood, A.M., Maltby, J., Stewart, N. and Joseph, S. (2008b). Conceptualizing gratitude and appreciation as a unitary personality trait. Personality and Individual Differences. 44, 621-632. 